\title{
Cárie dentária e práticas alimentares entre crianças de creches do município de São Paulo
}

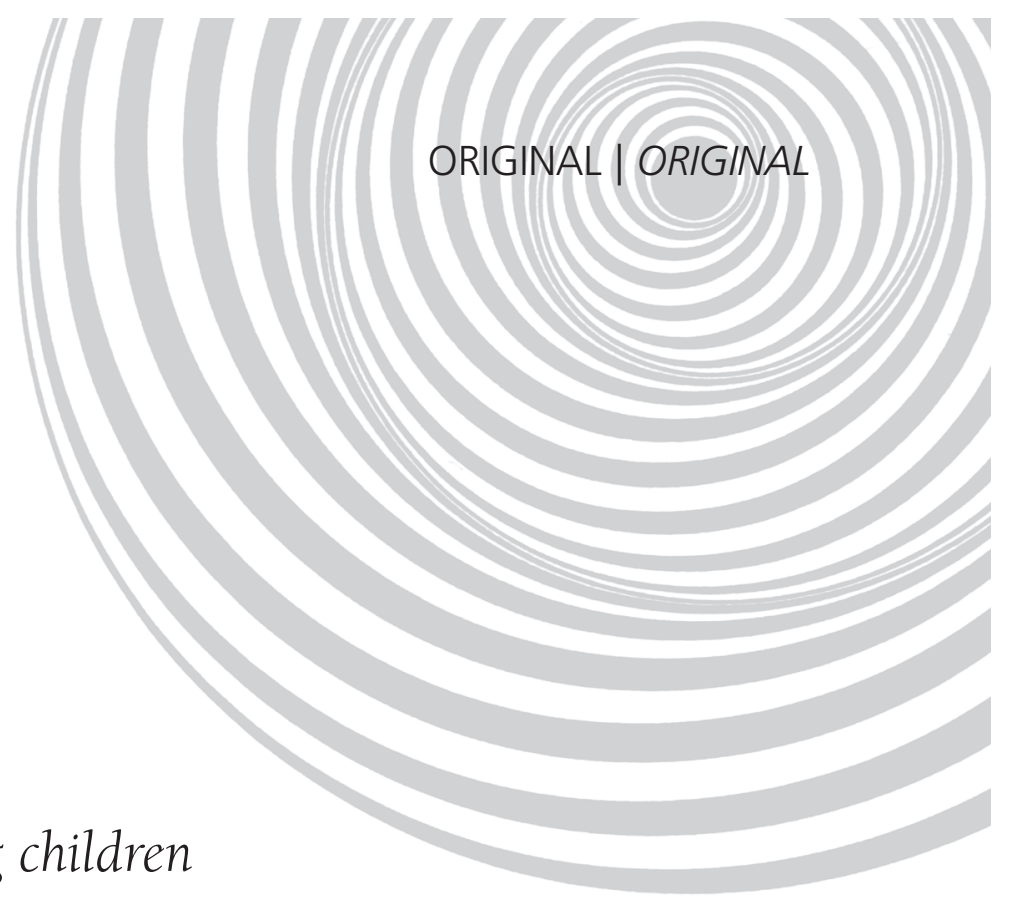

\author{
Dental caries and food practices among children \\ attending daycare centers in the \\ city of São Paulo, Brazil
}

Adriana Manrubia BIRAL'1

José Augusto de Aguiar Carrazedo TADDEI'

Daniela Forlin PASSONI ${ }^{1}$

Domingos PALMA ${ }^{1}$

RE S U M O

\section{Objetivo}

Este estudo tem como objetivo avaliar associações entre a cárie dentária e a introdução de alimentos complementares em crianças de 11 a 34 meses matriculadas em creches.

\section{Métodos}

Trata-se de estudo transversal com 288 crianças de oito creches do município de São Paulo, realizado em 2007. Para o diagnóstico da cárie dentária foi utilizado o Índice de Cárie Modificado, que foi investigado por uma equipe de três cirurgiãs-dentistas treinadas quanto à precisão e acurácia. A introdução de alimentos foi avaliada por meio de questionário pré-codificado e pré-testado. Para quantificar as associações foi utilizado o teste Qui-quadrado. Para análise multivariada foram ajustados modelos de regressão logística $(p<0,05)$.

\section{Resultados}

Foram examinadas 228 crianças com idade entre 11 e 34 meses ( $M=24$ meses; $D P=6,02)$, das quais 53,9\% eram do sexo masculino e 57,45\% frequentavam creches filantrópicas. A maioria da amostra (77,0\%) apresentou Índice de Cárie Modificado igual ou superior a 1, enquanto o índice médio encontrado foi de 3,8 cáries por criança. Como fatores de risco significantes, foram identificados o sexo masculino $(O R=1,815 ; p=0,03)$ e a escolaridade paterna inferior a oito anos $(O R=1,94 ; p=0,02)$. O modelo de regressão logística identificou a exposição a carboidratos simples como fator de risco independente após o controle dos efeitos de sexo e

\footnotetext{
1 Universidade Federal de São Paulo, Escola Paulista de Medicina, Departamento de Pediatria. R. Loefgreen, 1647, Vl. Clementino, 04040-032, São Paulo, SP, Brasil. Correspondência para/Correspondence to: JAAC TADDEI. E-mails: <taddei.dped@epm.br>; <ambiral@hotmail.com>; <nutsec@yahoo.com.br>.
} 
38 | AM BIRAL et al.

escolaridade paterna, responsável por aumento de 2,5 vezes nas chances de apresentar o Índice de Cárie Modificado igual ou superior a 1.

\section{Conclusão}

Atenção especial deve ser dada a esse grupo de indivíduos, adotando-se políticas preventivas em saúde bucal e formação de hábitos alimentares saudáveis nas creches.

Termos de indexação: Cárie dentária. Comportamento alimentar. Crianças. Hábitos alimentares.

\section{A B S T R A C T}

\section{Objective}

The present study investigated associations between the prevalence of dental caries and introduction of complementary foods in children aged 11 to 34 months attending daycare centers.

\section{Methods}

This cross-sectional study included 288 children from eight daycare centers in São Paulo, 2007. The modified decay-missing-filled index, used for diagnosis, was investigated by a team of three trained dentists aiming at precision and accuracy. Food introduction was assessed using a pre-codified and pre-tested questionnaire. The Chi-square test was used to quantify associations and logistic regression models $(p<0.05)$ were adjusted for multivariate analysis.

\section{Results}

The sample consisted of 228 children aged 11 to 34 months ( $M=24$ months, SD=6.02). Of these, 53.9\% were male and $57.45 \%$ attended philanthropic daycare centers. Seventy-seven percent of the sample had modified decay-missing-filled index $\geq 1$ and the average modified decay-missing-filled index of the population is 3.8. Significant risk factors according to modified decay-missing-filled index were being male $(O R=1.815, p=0.03)$ and paternal formal education of less than eight years $(O R=1.94, p=0.02)$. The logistic regression model identified the exposure to simple carbohydrates as an independent risk factor, after controlling for the effects of sex and parental educational. Such exposure increased the chances of having modified decay-missing-filled index $\geq 1$ by 2.5 times.

\section{Conclusion}

Special attention should be given to this group of individuals, implementing preventive policies in oral health and building healthy food habits in daycare centers.

Indexing terms: Dental caries. Feeding behavior. Child. Food habits.

\section{N T R O D U ÇÃ O}

A cárie dental é a doença crônica mais comum na infância, constituindo um grande problema de saúde pública mundial. Um fator importante que deve ser levado em consideração é que ela pode ser prevenida e controlada'.

O último levantamento epidemiológico nacional em saúde bucal encontrou uma prevalência de 26,85\% na experiência de cárie dentáriaem crianças entre 18 e 36 meses, existindo um evidente incremento com o avanço da idade, independentemente do sexo².

A cárie dentária é uma doença infecciosa, transmissível, multifatorial e que resulta de uma combinação de três principais fatores: hospedeiro, microbiota e substrato. Entretanto, a cárie dentária não pode ser explicada meramente por uma relação causal entre esses três fatores. É resultado de interações mais complexas, envolvendo múltiplos determinantes que interferem nos fatores principais e, a menos que seja cuidadosamente controlada, continuará a progredir e se desenvolver ${ }^{3,4}$.

A cariologia se desenvolveu explicando o enorme impacto desses três principais achados. Primeiro, o papel da nutrição, considerando que esta poderia tornar o dente mais susceptível ao ataque cariogênico, como é o caso da forte correlação entre o consumo de açúcar nas popu- 
lações e a experiência de cárie dentária. Segundo, o papel dos microorganismos, estabelecendo a cárie dentária como doença infecciosa e transmissível, associada principalmente ao Estreptococos mutans. Terceiro, o papel do flúor na água de abastecimento ${ }^{3}$.

A dieta assume uma grande importância na etiologia da doença cárie dentária, pois, além de fornecer o principal substrato, influencia na produção de ácidos, no tipo e quantidade de biofilme bacteriano, na composição de microorganismos, e na qualidade e quantidade de secreção salivar. A sacarose refinada proveniente da cana de açúcar e da beterraba sempre foi considerada como dissacarídeo mais cariogênico. A maior parte dos açúcares de adição contidos nos alimentos que compõem a dieta do brasileiro é formada pela sacarose ${ }^{5}$.

Do ponto de vista nutricional, a introdução precoce de alimentos pode ser desvantajosa, pois diminui a duração do aleitamento materno, interfere na absorção de nutrientes importantes do leite materno, aumenta o risco de contaminação, de reações alérgicas e do desenvolvimento de cárie dentária ${ }^{6,7}$.

A diversidade e o aumento da oferta de alimentos industrializados podem influenciar os padrões alimentares da população, principalmente a infantil, uma vez que os primeiros anos de vida se destacam como um período muito importante para o estabelecimento de hábitos alimentares. O consumo inadequado, excessivo e muito frequente desses alimentos pode comprometer a saúde nessa fase e na idade adulta. Muitos alimentos industrializados são ricos em gorduras e carboidratos refinados, apresentando elevado valor energético. Além disso, o aumento do consumo de alimentos industrializados pode reduzir o consumo de alimentos in natura ${ }^{8}$.

Considerando o aumento contínuo e gradativo do número de crianças frequentadoras de creches, instituições onde são parcialmente definidos os hábitos alimentares e de higiene oral, torna-se relevante o estudo da ocorrência da cárie dentária entre essa população, bem como sua relação com práticas alimentares, estado nutricional, história clínica e características sociodemográficas 9 . Portanto, o objetivo deste trabalho é avaliar a associação entre a cárie dentária e as práticas alimentares nas crianças matriculadas em creches.

\section{MÉ TOD OS}

O presente estudo utiliza informações de um inquérito com crianças frequentadoras de creches públicas e filantrópicas do município de São Paulo, em $2007^{10}$.

A partir do universo de 36 creches pertencentes à Coordenadoria de Educação de Santo Amaro, localizadas na Região Central do Município de São Paulo, iniciou-se o processo de seleção. Na primeira etapa da seleção, as creches foram localizadas por contatos telefônicos e visitas pessoais. Foram excluídas creches que haviam participado de pesquisas em saúde, que não tinham berçário e que não aceitaram participar dos projetos, resultando em 18 creches participantes em potencial.

Na segunda etapa, as 18 creches foram classificadas segundo critérios de prioridades. Foram priorizados os seguintes critérios em ordem decrescente de valor: maior número de crianças, maior número de educadores, segurança dos pesquisadores, facilidade de transporte e acesso a suas dependências, e existência de regras de admissão que garantissem o atendimento exclusivo a famílias de baixa renda. A partir dessa metodologia, foram selecionadas 8 creches públicas e filantrópicas melhor classificadas para os inquéritos $^{11 .}$.

A população deste estudo foi constituída por 228 crianças, correspondendo à totalidade daquelas que frequentavam regularmente as oito creches selecionadas. Apresentavam faixa etária entre 11 e 34 meses, época da vida em que se define o consumo de sacarose, assim representando um grupo de risco para o aparecimento da cárie. A pesquisa abrangeu o período de outubro a dezembro de 2007. 
Um questionário estruturado e pré-codificado foi elaborado e utilizado para a coleta de dados, incluindo variáveis demográficas, clínicas, epidemiológicas, socioeconômicas e ambientais. Visando á uniformidade dos procedimentos de campo por parte dos entrevistadores, foi criado um manual com normas e conceitos para preenchimento desse instrumento ${ }^{12}$.

A coleta dos dados foi realizada nas creches por meio de entrevistas com as mães ou responsáveis e avaliação odontológica. Todos os procedimentos foram padronizados e testados, na etapa de pré-teste do projeto, pela equipe de campo multiprofissional composta por pediatra e nutricionistas pós-graduandos.

\section{Índice de cárie dentária}

O exame clínico intrabucal foi realizado por uma cirurgiã-dentista através de uma abordagem sistemática por quadrantes, com a colaboração de uma cirurgiã-dentista especialista auxiliar para contenção da criança, e uma cirurgiã-dentista auxiliar para anotação na ficha clínica especialmente desenvolvida para este estudo.

As crianças foram posicionadas deitadas, em posição horizontal sobre o trocador de fralda, com a examinadora posicionada à frente da criança para realizar o exame clínico, e a auxiliar para imobilizá-la.

Uma lanterna de mão com espectro de coloração azul-branca marca Maglite ${ }^{\circledR}$ foi utilizada para a visualização direta da cavidade bucal. Após a imobilização e colocação do abridor de boca, lateralmente, entre os arcos superiores e inferiores da boca da criança, teve início avaliação intrabucal $^{13}$. Com auxílio da lanterna de mão e espátula de madeira avaliou-se primeiro a presença ou ausência de biofilme bacteriano (placa bacteriana) nas faces vestibulares dos incisivos centrais superiores. As superfícies dentais foram então limpas e secas com a utilização de gaze, conforme preconizado por Bonecker ${ }^{14}$, iniciando-se a avaliação das mesmas quanto à presença de lesão de mancha branca, cavitações, restaurações e fraturas.

A ficha clínica continha a identificação do paciente e um odontograma. Os critérios e códigos utilizados foram explicados durante o treinamento e calibração para todos os membros da pesquisa.

\section{Critérios para o diagnóstico}

Para descrever a porcentagem de crianças afetadas, utilizou-se o Índice de Cárie Modificado (ceo-mod), onde: (c) cariados, (e) indicados para extração, (o) obturados e (mod) mancha branca. Obtiveram-se dois grupos: crianças que apresentaram alguma experiência de cárie dentária (ceo-mod $\geq 1$ ) e crianças que nunca tiveram essa experiência (ceo-mod=0). No caso de dúvida no diagnóstico entre cárie dentáriaou mancha branca, o dente foi considerado hígido ${ }^{15,16}$.

A introdução de alimentos e o aleitamento materno foram avaliados, a partir dos questionários preenchidos. Para cada um dos alimentos, foi preenchida a idade (em meses) informada da introdução, até o momento do estudo.

Foram analisadas as seguintes variáveis:

- Aleitamento materno a partir das variáveis: aleitamento à época, tempo de aleitamento exclusivo e aleitamento total.

- Idade de introdução dos alimentos naturais e industrializados: foram considerados alimentos naturais: água, chá, café, mel, suco de fruta natural, papa de frutas, papa de legumes, feijão, verduras, ovo, caldo de carne, carne de boi, carne de frango, fígado e peixe. Os industrializados foram: embutidos, salgadinho, iogurte, gelatina, refrigerante, suco artificial, bolacha recheada, macarrão instantâneo (miojo), frituras de imersão, açúcar, bala/pirulito/chocolate e espessantes.

Para dosagem dos níveis de hemoglobina foi utilizado um hemoglobinômetro portátil da marca HemoCue - $\beta$ Hemoglobin Photometer ${ }^{\circledR}$, que se baseia na leitura fotométrica sanguínea 
com a utilização de microcuvetas $\beta$ hemoglobin. O sistema HemoCue, que oferece resultados expressos em gramas por decilitro sem necessidade de cálculos em 30 a 50 segundos, é comparável às técnicas padrão de laboratório para medida do nível de hemoglobina ${ }^{17}$. Considerou-se anemia a concentração de hemoglobina inferior a $11,0 \mathrm{~g} / \mathrm{dL}^{18}$.

As crianças foram pesadas em balança pediátrica digital modelo BP Baby, marca Filizola ${ }^{\circledR}$, com capacidade mínima de $125 \mathrm{~g}$ e máxima de $15 k$, graduada a cada $5 \mathrm{~g}$. Para a medida da estatura foi utilizada a régua antropométrica de cursor móvel da Sociedade Brasileira de Pediatria, graduada a cada $0,5 \mathrm{~cm}$, até $120 \mathrm{~cm}$. Os procedimentos antropométricos adotados foram os recomendados internacionalmente. Para quantificar desvios nutricionais utilizou-se o escore-Z. O padrão de referência para idade e sexo adotado foi o da Organização Mundial de Saúde (OMS) ${ }^{19}$.

Os questionários foram avaliados quanto a sua consistência interna. As informações foram transcritas em bancos de dados com dupla digitação e posterior validação, visando à correção de eventuais erros.

Para análise dos dados foi criada a variável de tempo de exposição a cada um dos Alimentos Cariogênicos (AC), a partir da idade em meses da introdução dos $A C$, subtraída da data do inquérito. Sucessivamente foi criada a variável tempos proporcionais de exposição de cada AC, correspondendo ao tempo de exposição aos AC dividido pelo tempo de vida de cada participante.

Para dicotomização das variáveis foi utilizado o percentil 25 do tempo proporcional de exposição ao açúcar de adição.

A partir da associação entre o ceo-mod e o tempo de exposição dicotomizado, foram identificadas as variáveis com maior potencial cariogênico. Dessa forma, os três alimentos - bala, refrigerante e salgadinho -, pela alta correlação de sacarose e uso frequente entre os indivíduos da amostra, permitiram identificar as crianças com Exposição precoce a Carboidratos Simples (ECS).
Todas as crianças do percentil > 25 (que ainda não consumiam algum desses três alimentos) ocuparam a categoria de introdução não precoce para ECS $(p>25)$.

Em sequência, foram realizadas análises de consistência dos dados e estatísticas descritivas univariadas e bivariadas. Para quantificar as associações, foi utilizado o teste Qui-quadrado. Para análise multivariada foram ajustados modelos de regressão logística. Variáveis com $p<0,20$ nas análises bivariadas foram incluídas na modelagem, permanecendo apenas aquelas que apresentaram $p<0,05$ na análise multivariada. Os pacotes estatísticos utilizados foram o Epi Info ${ }^{\text {TM }} 2008$ e o Statistical Package for the Social Sciences (SPSS) ${ }^{18}$.

O inquérito evidenciou que não são realizadas práticas de higiene oral nas creches, não existindo escovas ou outros equipamentos para esse fim. Nenhuma das crianças incluídas na amostra havia recebido cuidados odontológicos curativos ou preventivos. O único ponto que se pode inferir é que, por serem crianças residentes do município de São Paulo, consumiam água fluoretada.

O estudo foi aprovado pelo Comitê de Ética em Pesquisa da Universidade Federal de São Paulo/Hospital São Paulo, sob Protocolo n 1279/ 09, em 21-09-2009, tendo todos os participantes/ responsáveis assinado um Termo de Consentimento Livre e Esclarecido antes de sua inclusão na amostra.

As crianças que apresentaram cárie dentária, anemia, desvios nutricionais ou outras doenças foram encaminhadas para tratamento em unidade assistencial.

\section{RESULTADOS}

Ao apresentar os resultados deste estudo e suas implicações, é necessário entender suas possíveis limitações. Nos estudos de prevalência não é possível determinar a precedência do suposto fator de risco em relação ao problema de 
saúde em questão, condição necessária para a caracterização de uma relação de causa e feito. Todavia, ressalta-se que estudos transversais são frequentemente conduzidos para prover estimativas de problemas de saúde e, também, por se prestarem para a realização de inferências etiológicas, além de serem particularmente apropriados para subsidiar planejamento dos serviços de saúde ${ }^{20}$.

Foram examinadas 228 crianças com idade entre 11 e 34 meses $(24 \pm 6,02)$, das quais $53,9 \%$ eram do sexo masculino e $57,45 \%$ frequentavam creches filantrópicas.

Da totalidade $77,0 \%$ apresentaram alguma alteração para o índice (ceo-mod $\geq 1$ ) e $72,37 \%$ apresentaram placa bacteriana. 0 ceo-mod médio da amostra foi de 3,8.

A Tabela 1 mostra que, em relação ao ceo-mod, identificaram-se como fatores de risco com significância estatística o sexo masculino $(\mathrm{OR}=1,815 ; p=0,03)$, a escolaridade paterna inferior a oito anos $(\mathrm{OR}=1,94 ; p=0,02)$ e a presença de placa bacteriana $(O R=5,43 ; p=0,0000)$.

A Tabela 2 mostra as associações entre o tempo de exposição aos alimentos e a presença ou não de cárie dental ou mancha branca. Evidencia-se que quase a totalidade dos alimentos introduzidos antes dos 11 meses $(p<25)$ leva a maiores riscos de alterações odontológicas. Observa-se que tais associações ocorrem também para alimentos como suco de laranja e papa de frutas, que estão preconizados a partir dos 6 meses de vida.

O modelo logístico apresentado na Tabela 3 apresentou resultados considerando o componente ceo-mod como variável de desfecho, em relação à variável independente ECS controlando sexe escolaridade paterna.

A regressão logística permitiu identificar a ECS como fator de risco independente que, mesmo após o controle dos efeitos do sexo e da escolaridade paterna, ainda é responsável pelo aumento de 2,5 vezes na chance de apresentar o índice ceo-mod $\geq 1$.

\section{DIS C U S S Ã O}

O Índice de Cárie Dentária tem boa confiabilidade, pois foi obtido a partir de protocolos de excelência e realizado por uma única equipe de profissionais devidamente treinados, o que garante alto nível de precisão, com variabilidade de inter-observadores ausente.

A análise das variáveis socioeconômicas e culturais da família demonstrou que $75,0 \%$ das crianças com pai com escolaridade inferior a 8 anos apresentaram alterações bucais ( $\mathrm{OR}=1,94$, $p<0,02)$. Um estudo realizado por Brandão et al. ${ }^{21}$ também encontrou associação entre cárie dentária e escolaridade paterna, indicando que $58,7 \%$ das 110 crianças com cárie precoce tinham pai com menos de oito anos de escolaridade $(p=0,01)$. Muitos estudos apontam que pais com menor escolaridade são um fator de risco para o desenvolvimento da doença cárie denta|22-24. Essa característica (baixa escolaridade) pode apontar condição socioeconômica desfavorável ${ }^{22}$ que, segundo Peres et al. ${ }^{25}$, leva as crianças a apresentarem maior prevalência e severidade de cárie dentária.

Quando observada a presença do ceo-mod $\geq 1$, o sexo masculino apresentou $72,4 \%$ da amostra. De acordo com os estudos de Cerqueira et al. ${ }^{26}$, Vasconcelos et al. ${ }^{27}$ e de Ribeiro et al. ${ }^{28}$, foi observada uma distribuição relativamente homogênea em relação ao sexo, embora tenha ocorrido uma discreta representatividade para o masculino.

A população estudada apresentou índice de ceo-mod de 3,8, que representa o número médio de dentes afetados por indivíduo. Os mesmos resultados insatisfatórios foram encontrados no estudo de Rihs et al. ${ }^{29}$, que observaram um ceo-mod de 3,81 entre pré-escolares com idade inferior a cinco anos, tanto na rede pública quanto na privada.

Em termos percentuais, $77 \%$ da amostra deste estudo apresentaram o ceo-mod $\geq 1$. Mais uma vez, esses resultados mostram a necessidade de ações preventivas multidisciplinares e emer- 
Tabela 1. Prevalências e Odds Ratio com seus respectivos intervalos de confiança para variáveis associadas à presença ou à ausência de cárie dental ou mancha branca (ceo-mod $\geq 1$ ), em creches públicas e filantrópicas de um subdistrito do município de São Paulo (SP), 2007.

\begin{tabular}{|c|c|c|c|c|c|c|c|}
\hline \multirow[t]{2}{*}{ Variáveis } & \multirow{2}{*}{$\begin{array}{c}\mathrm{n} \text { total } \\
228\end{array}$} & \multicolumn{2}{|c|}{ ceo-mod $\geq 1$} & \multirow[t]{2}{*}{ OR } & \multirow[t]{2}{*}{ IC95\% } & \multirow[t]{2}{*}{$\chi^{2}$} & \multirow[t]{2}{*}{$p^{*}$} \\
\hline & & $n$ & $\%$ & & & & \\
\hline \multicolumn{8}{|l|}{ Sexo } \\
\hline $\begin{array}{l}\text { Masculino } \\
\text { Feminino }\end{array}$ & & $\begin{array}{l}89 \\
62\end{array}$ & $\begin{array}{l}72,4 \\
59,0\end{array}$ & 1,815 & $1,04-3,16$ & 4,486 & $0,003^{*}$ \\
\hline \multicolumn{8}{|l|}{ Creche } \\
\hline $\begin{array}{l}\text { Pública } \\
\text { Filantrópica }\end{array}$ & & $\begin{array}{l}66 \\
85\end{array}$ & $\begin{array}{l}68,0 \\
64,0\end{array}$ & 1,152 & $0,65-2,01$ & 0,240 & 0,061 \\
\hline \multicolumn{8}{|c|}{ Escolaridade do Pai } \\
\hline $\begin{array}{l}<8 \text { anos } \\
\geq 8 \text { anos }\end{array}$ & & $\begin{array}{l}66 \\
85\end{array}$ & $\begin{array}{l}75,0 \\
60,7\end{array}$ & 1,94 & $1,07-3,5$ & 4,930 & $0,002^{*}$ \\
\hline \multicolumn{8}{|c|}{ Escolaridade da Mãe } \\
\hline $\begin{array}{l}<8 \text { anos } \\
\geq 8 \text { anos }\end{array}$ & & $\begin{array}{l}53 \\
98\end{array}$ & $\begin{array}{l}68,8 \\
64,9\end{array}$ & 1,19 & $0,66-2,14$ & 0,350 & 0,055 \\
\hline \multicolumn{8}{|c|}{ Tempo de creche } \\
\hline $\begin{array}{l}<14 \text { meses } \\
\geq 14 \text { meses }\end{array}$ & & $\begin{array}{c}24 \\
127\end{array}$ & $\begin{array}{l}60,0 \\
67,6\end{array}$ & 0,72 & $0,35-1,54$ & 0,840 & 0,035 \\
\hline \multicolumn{8}{|c|}{ Moradia Construção } \\
\hline $\begin{array}{l}\text { Alvenaria } \\
\text { Outro }\end{array}$ & & $\begin{array}{c}145 \\
6\end{array}$ & $\begin{array}{l}65,6 \\
85,7\end{array}$ & 0,31 & $0,03-2,68$ & 1,220 & 0,026 \\
\hline \multicolumn{8}{|l|}{ Vacina } \\
\hline $\begin{array}{l}\text { Em dia } \\
\text { Atraso }\end{array}$ & & $\begin{array}{c}141 \\
10\end{array}$ & $\begin{array}{l}65,3 \\
83,3\end{array}$ & 0,37 & $0,08-1,76$ & 1,650 & 0,019 \\
\hline \multicolumn{8}{|c|}{ Nascimento com doença ${ }^{\mathrm{a}}$} \\
\hline $\begin{array}{l}\text { Sim } \\
\text { Não }\end{array}$ & & $\begin{array}{c}22 \\
128\end{array}$ & $\begin{array}{l}57,9 \\
67,7\end{array}$ & 0,65 & $0,32-1,33$ & 1,360 & 0,024 \\
\hline \multicolumn{8}{|l|}{ Prematura } \\
\hline $\begin{array}{l}\text { Sim } \\
\text { Não }\end{array}$ & & $\begin{array}{c}21 \\
130\end{array}$ & $\begin{array}{l}72,4 \\
65,3\end{array}$ & 1,39 & $0,58-3,3$ & 0,560 & 0,040 \\
\hline \multicolumn{8}{|c|}{ Baixo peso ao nascer } \\
\hline $\begin{array}{l}\text { Peso } \leq 2500 \mathrm{~g} \\
\text { Peso }>2500 \mathrm{~g}\end{array}$ & & $\begin{array}{c}16 \\
135\end{array}$ & $\begin{array}{l}64,0 \\
66,5\end{array}$ & 0,89 & $0,37-2,13$ & 0,060 & 0,080 \\
\hline \multicolumn{8}{|c|}{ Peso insuficiente à épocab } \\
\hline $\begin{array}{l}\text { Sim } \\
\text { Não }\end{array}$ & & $\begin{array}{l}53 \\
98\end{array}$ & $\begin{array}{l}61,6 \\
69,0\end{array}$ & 0,72 & $0,42-1,2$ & 1,300 & 0,023 \\
\hline \multicolumn{8}{|l|}{ Anemia } \\
\hline $\begin{array}{l}<11 \mathrm{~g} / \mathrm{dL} \\
\geq 11 \mathrm{~g} / \mathrm{dL}\end{array}$ & & $\begin{array}{c}28 \\
123\end{array}$ & $\begin{array}{l}62,2 \\
67,2\end{array}$ & 0,8 & $0,4-1,58$ & 0,400 & 0,050 \\
\hline \multicolumn{8}{|c|}{ Placa bacteriana } \\
\hline $\begin{array}{l}\text { Sim } \\
\text { Não }\end{array}$ & & $\begin{array}{c}127 \\
24\end{array}$ & $\begin{array}{l}77,0 \\
38,1\end{array}$ & 5,43 & $2,9-10,14$ & 30,800 & $0,000^{*}$ \\
\hline \multicolumn{8}{|c|}{ Desmame aos 6 meses } \\
\hline $\begin{array}{l}\text { Sim } \\
\text { Não }\end{array}$ & & $\begin{array}{l}68 \\
83\end{array}$ & $\begin{array}{l}68,7 \\
64,3\end{array}$ & 1,21 & $0,69-2,12$ & 0,470 & 0,049 \\
\hline \multicolumn{8}{|c|}{ Aleitamento exclusivo por 3 meses } \\
\hline $\begin{array}{l}\text { Sim } \\
\text { Não }\end{array}$ & & $\begin{array}{l}69 \\
82\end{array}$ & $\begin{array}{l}63,3 \\
68,9\end{array}$ & 0,77 & $0,44-1,34$ & 0,790 & 0,037 \\
\hline \multicolumn{8}{|c|}{ Aleitamento à época } \\
\hline $\begin{array}{l}\text { Sim } \\
\text { Não }\end{array}$ & & $\begin{array}{c}145 \\
6\end{array}$ & $\begin{array}{l}65,9 \\
75,0\end{array}$ & 0,644 & $0,12-3,27$ & 0,280 & 0,059 \\
\hline
\end{tabular}

a Tempo de permanência no berçário $>3$ dias.

b $\leq-2 z$ da relação peso para idade.

* Diferença significante no nível 5\%, segundo o teste Qui-quadrado. Ceo-mod: Índice de Cárie Modificado; OR: Odds Ratio; IC95\%: Intervalo de Confiança de 95\%; $\chi^{2}$ : Qui-quadrado. 
44 AM BIRAL et al.

Tabela 2. Prevalência e razão de chance bruto com seus respectivos intervalos de confiança de $95 \%$ para variáveis de tempo de exposição aos alimentos com corte no percentil 25 relacionados ao ceo-mod $\geq 1$, obtidos por meio do teste Qui-quadrado. São Paulo (SP), 2007.

\begin{tabular}{|c|c|c|c|c|c|c|c|c|c|}
\hline \multirow{3}{*}{$\begin{array}{l}\text { Variáveis } \\
\text { Açúcar }\end{array}$} & \multirow{2}{*}{$\frac{\mathrm{n} \text { total }}{228}$} & \multicolumn{2}{|c|}{ ceo-mod $\geq 1$} & \multicolumn{2}{|c|}{ ceo-mod=0 } & \multirow[t]{2}{*}{ OR } & \multirow[t]{2}{*}{ IC95\% } & \multirow[t]{2}{*}{$\chi^{2}$} & \multirow[t]{2}{*}{$p^{*}$} \\
\hline & & $\mathrm{n}$ & $\%$ & $\mathrm{n}$ & $\%$ & & & & \\
\hline & & & & & & & & & \\
\hline$p<25$ & & 179 & 78,5 & 49 & 21,5 & 2,04 & $1,07-3,9$ & 4,83 & 0,020 \\
\hline$p>25$ & & 26 & 56,1 & 23 & 43,9 & & & & \\
\hline \multicolumn{10}{|l|}{ Bala } \\
\hline$p<25$ & & 125 & 70,6 & 52 & 29,4 & 2,311 & $1,22-4,3$ & 6,82 & $0,008^{*}$ \\
\hline$p>25$ & & 26 & 51 & 25 & 49,0 & & & & \\
\hline \multicolumn{10}{|c|}{ Suco artificial } \\
\hline$p<25$ & & 113 & 68,1 & 53 & 31,9 & 1,34 & $0,73-2,46$ & 0,92 & 0,330 \\
\hline$p>25$ & & 38 & 61,3 & 24 & 38,7 & & & & \\
\hline \multicolumn{10}{|l|}{ Miojo } \\
\hline$p<25$ & & 120 & 69,0 & 54 & 31,0 & 1,64 & $0,88-3,08$ & 2,46 & 0,110 \\
\hline$p>25$ & & 31 & 57,4 & 23 & 42,6 & & & & \\
\hline \multicolumn{10}{|c|}{ Suco natural } \\
\hline$p<25$ & & 123 & 71,5 & 49 & 28,5 & 2,51 & $1,35-4,66$ & 8,74 & $0,003^{*}$ \\
\hline$p>25$ & & 28 & 50,0 & 28 & 50,0 & & & & \\
\hline \multicolumn{10}{|l|}{ Chá } \\
\hline$p<25$ & & 123 & 71,5 & 49 & 28,5 & 2,51 & $1,35-4,66$ & 8,74 & $0,003^{*}$ \\
\hline$p>25$ & & 28 & 50,0 & 28 & 50,0 & & & & \\
\hline \multicolumn{10}{|c|}{ Refrigerante } \\
\hline$p<25$ & & 114 & 72,2 & 44 & 27,8 & 2,32 & $1,28-4,14$ & 8,07 & $0,004^{*}$ \\
\hline$p>25$ & & 37 & 52,9 & 33 & 47,1 & & & & \\
\hline \multicolumn{10}{|c|}{ Papa de frutas } \\
\hline$p<25$ & & 127 & 71,8 & 50 & 28,2 & 2,85 & $1,50-5,41$ & 10,79 & $0,001^{*}$ \\
\hline$p>25$ & & 24 & 47,1 & 27 & 52,9 & & & & \\
\hline \multicolumn{10}{|c|}{ Bolacha recheada } \\
\hline$p<25$ & & 119 & 68,0 & 56 & 32,0 & 1,39 & $0,73-2,63$ & 1,05 & 0,300 \\
\hline$p>25$ & & 32 & 60,4 & 21 & 39,6 & & & & \\
\hline \multicolumn{10}{|l|}{ Fritura } \\
\hline$p<25$ & & 108 & 74,5 & 37 & 25,5 & 2,71 & $1,53-4,8$ & 12,13 & $0,000^{*}$ \\
\hline$p>25$ & & 43 & 51,8 & 40 & 48,2 & & & & \\
\hline \multicolumn{10}{|l|}{ Ovo } \\
\hline$p<25$ & & 124 & 71,7 & 49 & 28,3 & 2,62 & $1,4-4,89$ & 9,51 & $0,002^{*}$ \\
\hline$p>25$ & & 27 & 49,1 & 28 & 50,9 & & & & \\
\hline \multicolumn{10}{|c|}{ Embutidos } \\
\hline$p<25$ & & 110 & 71,0 & 45 & 29,0 & 1,90 & $1,07-3,4$ & 4,86 & $0,027^{*}$ \\
\hline$p>25$ & & 41 & 56,2 & 32 & 43,8 & & & & \\
\hline \multicolumn{10}{|l|}{ logurte } \\
\hline$p<25$ & & 122 & 69,7 & 53 & 30,3 & 1,9 & $1,01-3,57$ & 4,09 & $0,043^{*}$ \\
\hline$p>25$ & & 29 & 54,7 & 24 & 45,3 & & & & \\
\hline \multicolumn{10}{|c|}{ Salgadinho } \\
\hline$p<25$ & & 121 & 69,9 & 52 & 30,1 & 1,93 & $1,04-3,61$ & 4,42 & $0,034^{*}$ \\
\hline$p>25$ & & 30 & 54,5 & 25 & 45,5 & & & & \\
\hline$E C S^{a}$ & & & & & & & & & \\
\hline$p<25$ & & 91 & 75,2 & 30 & 24,8 & 2,37 & $1,35-4,16$ & 9,29 & $0,002^{*}$ \\
\hline$p>25$ & & 60 & 56,1 & 47 & 43,9 & & & & \\
\hline
\end{tabular}

a Exposição a Carboidrato Simples, escore descrito nos métodos.

* Diferença significante no nível 5\%, segundo o teste Qui-quadrado. Ceo-mod: Índice de Cárie Modificado; OR: Odds Ratio; IC95\%: Intervalo de Confiança de 95\%; $\chi^{2}$ : Qui-quadrado. 
Tabela 3. Modelo de regressão logística ajustado para o índice ceo-mod, São Paulo (SP), 2007.

\begin{tabular}{lcccc}
\hline & \multicolumn{3}{c}{ IC95\% } & \\
\cline { 2 - 5 } & OR & Inferior & Superior & Significância \\
\hline ECS & 2,528 & 1,418 & 4,507 & 0,002 \\
Escolaridade pai $<8$ anos & 1,950 & 1,060 & 3,587 & 0,032 \\
Sexo masculino & 1,835 & 1,032 & 3,263 & 0,039 \\
\hline
\end{tabular}

ECS: Exposição a Carboidrato Simples; Escore descrito nos métodos; OR: Odds Rattio; IC95\%: Intervalo de Confiança de $95 \%$.

genciais, a fim de melhorar as condições de saúde oral dessa população, a qual, em sua maioria, já se apresenta alterada aos dois anos de idade.

Segundo a Organização Mundial da Saúde ${ }^{15}$, para a realização de levantamentos epidemiológicos, somente lesões cavitadas são consideradas e assim computadas no índice de cárie. Dessa forma, os dentes com lesões ativas de mancha branca, no estágio inicial da doença, são considerados dentes hígidos. Entretanto, a mancha branca nos primeiros meses ou anos de vida, embora seja uma medida indireta realizada rotineiramente em levantamentos epidemiológicos, pode identificar as crianças com maior risco de desenvolvimento de cárie dentária. Por outro lado, a identificação precoce da mancha branca permite que se promova a remineralização do esmalte e pode contemplar a questão, minimizando o risco de evolução para a cárie dentária propriamente dita, esta já irreversível|15,21.

O modelo logístico apresentado neste estudo demonstrou um risco de $2,5(p=0,002)$ maior para a presença de cárie dentária e/ou mancha branca como variável de desfecho, em relação à variável independente ECS. Essa variável foi criada com o objetivo de mostrar o quão precocemente são introduzidos alimentos como balas, refrigerantes e salgadinhos, alimentos que, além de pouco nutritivos e cariogênicos, são ainda normalmente ricos em gorduras saturadas e pobres em fibras alimentares.

Os Dez Passos da Alimentação Saudável orientam que para uma criança menor de dois anos é desnecessária a utilização do açúcar. Afirmam também que essa atitude permite que a criança não se desinteresse pelos cereais, verduras e legumes, que têm outros sabores ${ }^{30}$.
Entre famílias brasileiras residentes em regiões metropolitanas, o consumo de açúcar e refrigerantes participa com $13,7 \%$ da energia consumida pelos indivíduos, caracterizando o aumento no consumo (já excessivo) de açúcar refinado e refrigerantes como traço marcante e negativo da evolução do padrão alimentar entre 1988 e 1996. Salienta-se que esse valor está acima do que a OMS recomenda como limite populacional máximo para o consumo de açúcar, isto é, $10,0 \%$ do consumo energético tota ${ }^{31,32}$.

Merece destaque a afirmação citada por Brandão et al. ${ }^{21} \mathrm{em}$ seu estudo com 110 crianças de 24 a 35 meses, matriculadas em 7 Centros Municipais de Educação e Recreação da cidade de Araraquara, onde a cárie dentária precoce foi observada em $28,2 \%$ das crianças (20,9\% com lesões não cavitadas/manchas brancas, e 7,3\% com lesões cavitadas). Esse estudo mostrou que a preferência pelo açúcar é altamente influenciada pela maior exposição e disponibilidade desse produto, associada à urbanização. Além disso, hábitos adquiridos na infância influenciam fortemente o padrão alimentar durante os anos subsequentes, podendo tornar-se permanentes.

Os hábitos alimentares errados levam a maior prevalência da cárie dentária, já que tanto a quantidade de sacarose ingerida quanto a frequência de ingestão são importantes fatores envolvidos na etiologia da doença. A American Dietetic Association orienta que a nutrição é componente fundamental para a saúde bucal e que tanto a alimentação como a nutrição têm influência direta na progressão da cárie dentária ${ }^{33}$.

Saito et al. ${ }^{34}$ examinaram 156 crianças com idade de 18 a 48 meses, nascidas e residentes 
em Piracicaba, e regularmente matriculadas em creches da rede pública e privada. Também observaram que a maior prevalência de cárie dentária estava relacionada com a introdução precoce do açúcar na dieta. Das crianças com cárie dentária precoce, $100 \%$ das mães relataram o uso do açúcar na mamadeira e também o hábito de mamar antes de dormir.

Toloni et al. ${ }^{35}$ evidenciaram, ainda dentro desse mesmo programa, que houve introdução precoce de alimentos na dieta dessas crianças. Seu estudo revelou que o açúcar foi introduzido antes dos 12 meses para 87,0\% das crianças e que, apesar de parecer de uso tradicional, não é recomendado para essa faixa etária. A introdução de refrigerantes e sucos artificiais ocorreu até os 12 meses de idade para $56,5 \%$ e $63,6 \%$ das crianças, respectivamente. Além de conterem aditivos químicos, esses produtos têm sido alvo de intensa preocupação, pois apresentam elevado teor de açúcar e são desprovidos, em sua maioria, de micronutrientes.

O carboidrato, importante componente da dieta humana, tem recebido por parte da comunidade científica odontológica grande atenção no que diz respeito a seu papel como substrato para a microbiota bucal. Dentre os carboidratos fermentáveis, a sacarose tem sido universalmente indicada como a mais cariogênica, sendo também o açúcar mais presente na dieta familiar em quase todo o mundo ${ }^{36}$. A sacarose é o alimento cariogênico mais importante e mais amplamente utilizado pelo homem. Tem o poder de transformar alimentos não cariogênicos e anticariogênicos em cariogênicos ${ }^{37}$.

A alimentação tradicional à base de cereais, legumes e outros vegetais vem sendo substituída gradualmente por alimentos processados, de baixo valor nutricional, ricos em sacarose e gorduras, promovidos pela mídia como símbolo de status social. A adoção de hábitos alimentares saudáveis na infância contribui para o pleno crescimento e desenvolvimento da criança e para a prevenção de doenças, refletindo na qualidade de vida familiar. A identificação de fatores cole- tivos de risco à cárie dentária, representados pelos condicionantes sociais, econômicos e culturais, surge como forte instrumento para possibilitar à prática odontológica o entendimento do processo saúde-doença em grupos sociais ${ }^{38}$.

\section{O N CLUS Ã O}

A cárie dentária precoce, a mancha branca e o consumo de carboidratos simples foram claramente observados e associados na população estudada. Sugere-se que uma atenção especial deva ser dada para esse grupo de indivíduos, adotando-se políticas preventivas em saúde bucal, pautadas no controle dos fatores de risco para o desenvolvimento da cárie dentária.

\section{OLABORADORES}

AM BIRAL foi responsável pela análise de dados e redação. JAAC TADDEl foi responsável pela idealização do projeto e revisão da redação. DF PASSONI colaborou na coleta e interpretação de dados. D PALMA colaborou na pesquisa e redação.

\section{REFERÊ NCIAS}

1. Misra S, Tahmassebi JF, Brosnan M. Early childhood caries: a review. Dent Update. 2007; 34(9):556-8, 561-2, 564.

2. Brasil. Ministério da Saúde. Projeto SB Brasil 2003: condições de saúde bucal da população brasileira 2002-2003: resultados principais. Brasília: MS; 2004 [acesso 2011 jan 3]. Disponível em: <http:// www.apcd.org.br/anexos/projetos_sociais/ projeto_sb.pdf>.

3. Fejerskov O, Kidd EAM. Cariologia clínica e a dentística operatória no século XXI. In: Fejerskov O, Kidd EAM, organizadores. Cárie dentária: a doença e seu tratamento clínico. São Paulo: Santos; 2005.

4. Moreira M, Lavoranti OJ, Vicente VA. Avaliação epidemiológica e microbiológica da doença cárie em famílias de baixa renda. Rev Assoc Paul Cir Dent. 2007; 61(6):480-4.

5. Pereira DF. Fatores de risco associados à cárie dentária e ao alto nível de estreptococos mutans em crianças de 12 a 24 meses em creches do município de São Paulo - SP [doutorado]. São Paulo: Universidade de São Paulo; 2007. 
6. Parada $\mathrm{CMGL}$, Carvalhaes MABL, Jamas MT. Práticas de alimentação complementar em crianças no primeiro ano de vida. Rev Latino-Am Enfermagem. 2007; 15(2):282-9. doi: 10.1590/S0104-116 92007000200014.

7. Bussato ARM, Oliveira AF, Carvalho HSL. A influência do aleitamento materno sobre o estado nutricional de crianças e adolescentes. Rev Paul Pediatr. 2006; 24(3):249-54.

8. Saldiva SR, Escuder MM, Mondini L, Venâncio SI. Práticas alimentares de crianças de 6 a 12 meses e fatores maternos associados. J Pediatr. 2007; 83(1): 53-8. doi: 10.1590/S0021-75572007000100010.

9. Souza PC, Taddei JAAC. Efeito da freqüência à creche nas condições de saúde e nutrição de pré-escolares residentes em favelas da periferia de São Paulo, 1996. Rev Paul Pediatr.1998; 16(3):143-50.

10. Taddei JA, Oliveira MN, Konstantyner T. Impacto do treinamento de educadores de creches públicas/ filantrópicas nas práticas higiênico-dietéticas e na saúde/nutrição dos lactentes: Projeto Fapesp $\mathrm{n}^{\circ}$ 2006/02597-0. São Paulo: Unifesp; 2006 [acesso 2009 jul 15]. Disponível em: http://www.bv.fapesp. br/pt/projetos-regulares/21977/impactotreinamento-educadoras-creches-publicas/>.

11. Konstantyner T, Taddei JA, Oliveira MN, Palma D, Colugnati FA. Isolated and combined risks for anemia in children attending the nurseries of daycare centers. J Pediatr. 2009; 85(3):209-16. doi: 10.1590/S0021-75572009000300005.

12. Gregg MB. Field epidemiology. $3^{\text {nd }}$ ed. Oxford: Oxford University Press; 2008.

13. Corrêa MSNP, Ramires-Romito ACD, Zardetto CGDC. Indicadores e uso de abridores de boca na odontologia para bebês. In: Corrêa MSNP, organizador. Sucesso no atendimento odontopediátrico: aspectos psicológicos. São Paulo: Santos; 2002.

14. Bonecker M. Análise comparativa de estudos epidemiológicos de cárie dentária em crianças de 5 a 59 meses de idade do município de Diadema, São Paulo, Brasil - 1995 e 1997 [doutorado]. São Paulo: USP; 1999.

15. Organização Mundial de Saúde. Levantamento epidemiológico básico de saúde bucal. $4^{a}$ ed. São Paulo: Santos; 1999.

16. Pinto VG. Identificação do problema. In: Pinto VG, organizador. Saúde bucal coletiva. São Paulo: Santos; 2000.

17. Rosemblit J, Abreu CR, Szterling LN, Kutner JM, Hamerschalak N, Frutuoso $P$, et al. Evaluation of three methods for hemoglobin measurement in blood donor setting. Rev Paul Med. 1999; 117(3): 108-12.
18. De Maeyer EM. Preventing and controlling iron deficiency anaemia through primary health care. Geneva: WHO; 1989.

19. World Health Organization. Multicentre Growth Reference Study Group. WHO child growth standards: length/height-for-age, weight-for-age, weight-for-length, weight-for-height and body mass index-for-age: methods and development. Geneva: WHO; 2006.

20. Costa AJL, Nadanovsky P. Epidemiologia e bioestatística na pesquisa odontológica: desenhos de estudo epidemiológicos. São Paulo: Ateneu; 2005.

21. Brandão IM, Arcieri RM, Sundefeld ML, Moimaz SA. Cárie precoce: influência de variáveis sócio-comportamentais e do locus de controle da saúde em um grupo de crianças de Araraquara, São Paulo, Brasil. Cad Saúde Pública. 2006; 22(6):1247-56. doi: 10.1590/S0102-311X2006000600014.

22. Warren JJ, Weber-Gasparoni K, Marshall TA, Drake DR, Dehkordi-Vakil F, Kolker JL, et al. Factors associated with dental caries experience in 1-yearold children. J Public Health Dent. 2008; 68(2): 70-5. doi: 10.1111/j.1752-7325.2007.00068.x.

23. Caufield PW, Griffen AL. Dental caries: an infectious and transmissible disease. Pediatr Clin North Am. 2000; 47(5):1001-19.

24. Huntington NL, Kim IJ, Hughes CV. Caries-risk factors for hispanic children affected by early childhood caries. Pediatr Dent. 2002; 24:536-42.

25. Peres MAA, Lattore MRVO, Sheihan A, Peres KG, Barros SC, Hernandez PG. Determinantes sociais e biológicos da cárie dentária em crianças de 6 anos de idade: um estudo transversal alinhado numa coorte de nascidos vivos no sul do Brasil. Rev Bras Epidemiol. 2003; 6(4):296-306.

26. Cerqueira LM, Alves MSCS, Bonecker MJ, Pinho ALS. Estudo da prevalência de cárie e da dieta em crianças de 0 a 36 meses na cidade de Natal-RN. J Bras Odontol Odontoped Bebê. 1998; 2(9):351-6.

27. Vasconcelos NT, Melo T, Gavinha S. Estudo dos fatores etiológicos das cáries precoces da infância numa população de risco. Rev Port Estomatol Med Dent Cir Maxilofac. 2004; 45(2):69-77.

28. Ribeiro AG, Oliveira AF, Rosenblat A. Cárie precoce na infância: prevalência e fatores de risco em pré-escolares, aos 48 meses, na cidade de João Pessoa, Paraíba, Brasil. Cad Saúde Pública. 2005; 21(6): 1695-700.

29. Rihs LB, Sousa MLR, Cypriano S, Abdalla NM, Guidini DDN, Amgarten C. Atividade de cárie na dentição decídua, Indaiatuba, São Paulo, Brasil, 2004. Cad Saúde Pública. 2007; 23(3):593-600. doi: 10.1590/S0102-311X2007000300018. 
30. Vitolo MR, Bortolini GA, Feldens CA, Drachler M. Impactos da implementação dos 10 passos da alimentação saudável para crianças: ensaio de campo randomizado. Cad Saúde Pública. 2005; 21(5): 1448-57. doi: 10.1590/S0102-311X20050005000 18.

31. Monteiro CA, Mondini L, Costa RBL. Mudanças na composição e adequação nutricional da dieta familiar em áreas metropolitanas do Brasil 19881996. Rev Saúde Pública. 2000; 34(3):251-8. doi: 10.1590/S0034-89102000000300007.

32. World Health Organization. Diet, nutrition and the prevention of chronic diseases. Geneva: WHO; 1990. Report of WHO study Group. Technical Report Series 916.

33. Touger-Decker R, Mobley CC, American Dietetic Association. Position of the American Dietetic Association: oral health and nutrition. J Am Diet Assoc. 2003; 103(5):615-25. doi:10.1053/jada. 2003.50130

34. Saito SK, Deccico HMU, Santos MN. Efeito da prática de alimentação infantil e de fatores associados sobre a ocorrência da cárie dental em pré-escolares de 18 a 48 meses. Rev Odontol Univ São Paulo.
1999; 13(1):5-11. doi: 10.1590/S0103-06631999 000100004.

35. Toloni MHA, Longo-Silva G, Goulart RMM, Taddei JAAC. Introdução de alimentos industrializados e de alimentos de uso tradicional na dieta de crianças de creches públicas no município de São Paulo. Rev Nutr. 2011; 24(1):61-70. doi: 10.1590/S1415-5 2732011000100006.

36. Lima CMG, Watanabe MGC, Palha PF. Atenção precoce à saúde bucal: tarefa da equipe de saúde da família. Pediatria. 2006; 28(3):191-8.

37. Ribeiro NME, Ribeiro MAS. Aleitamento materno e cárie do lactente e do pré-escolar: uma revisão crítica. J Pediatr. 2004; 80(5 Supl):S199-S210. doi: 10.2223/JPED. 1241.

38. Batista LRV, EAM, Corso ACT. Alimentação, estado nutricional e condição bucal da criança. Rev Nutr. 2007; 20(2):191-6. doi: 10.1590/S1415-\$273200 7000200008 .
Recebido em: 15/2/2012

Versão final em: 26/9/2012 Aprovado em: 2/10/2012 